\title{
Algunas reflexiones sobre las declaraciones contractuales recepticias y la cláusula resolutoria expresa (a propósito de la Casación Nro. 1725-201 - Lima-Este)
}

\author{
Marco Antonio Ortega Piana*
}

Resumen.- El autor reflexiona respecto de la regla de receptividad en materia de declaraciones contractuales, con particular énfasis en el ejercicio de la cláusula resolutoria expresa. Para ello, se basa en la Casación Nro. 1725-2016-Lima-Este como jurisprudencia vinculante, a efectos de tener una visión crítica del sistema judicial peruano.

Abstract.- The author reflects towards the rule of receptivity in matter of contractual declarations, emphasizing the exercise of the expressly cancellation clause. For this purpose, he bases his argument on the Cassation 1725-2016-Lima-Este as binding jurisprudence, in order to develop a critical view of the Peruvian judicial system.

Abogado por la Pontificia Universidad Católica del Perú. Profesor de derecho civil patrimonial en la Universidad de Lima y en la Universidad ESAN. Consultor de CMS Grau. 


\section{Breve introducción}

Agradeciendo por la singular deferencia de FORSETI de invitarme a participar en una nueva de sus ediciones, el presente trabajo tiene como propósito realizar algunos comentarios, y compartir algunas reflexiones, de cómo entender la exigencia legal de receptividad tratándose de las declaraciones contractuales, atendiendo además al ejercicio de la cláusula resolutoria expresa.

Y para ello, quisiera recordar previamente lo expresado en cierto evento académico organizado hace ya algunos años por un reconocido centro de administración de arbitrajes de nuestro medio. Dos árbitros británicos fueron invitados a disertar sobre cierta materia arbitral, siendo que en determinado momento presentaron al derecho anglosajón como heredero del derecho romano, afirmación que generó reacciones inmediatas entre algunos participantes, quienes expresaron que la escuela del derecho civil, y no la del derecho común, era la verdadera heredera del derecho romano, derecho escrito. Esa «precisión» generó, a su vez, la rápida respuesta de uno de los expositores, quien expresó que se incurría en un error, porque al afirmarse que el derecho común era heredero del derecho romano no estaba destacándose aspectos formales sino sustantivos: El derecho romano era un derecho casuístico, siendo que sobre la base de dicha casuística se habían generado progresivamente un conjunto de principios y reglas que eran luego objeto de estudio jurídico y aplicación jurisdiccional, por lo que de lo concreto se pasaba a lo abstracto, pero sin olvidar en este último el antecedente fáctico que lo explicaba. En función a ello -prosiguió-, el derecho común también era casuístico, y a través de la práctica jurisdiccional se habían desarrollado grandes conceptos generales. En cambio -según continuó-, en los países del derecho civil, ocurría exactamente lo contrario, porque de la casuística inicial se habían elaborado reglas abstractas de tal intensidad que, olvidando el supuesto de hecho que las explicaban, generaban múltiples e inclusive contradictorias interpretaciones, muchas de ellas muy alejadas de la realidad que les había dado origen, siendo que luego era un auténtico problema aplicarlas judicialmente en los casos concretos, máxime cuando no se daba un protagonismo especial al derecho vivo, al derecho jurisprudencial, identificándose ley con norma escrita abstracta.

El tema merece reflexión. En el estudio del derecho, la jurisprudencia -sea vinculante o no- no puede ser ignorada, porque representa la aplicación concreta de la norma legal abstracta, para bien o para mal; y desde que se postula que el estudiante de derecho debe tener una visión crítica del sistema jurídico, ello implica que también debe 
conocer y pronunciarse sobre la manera en que los jueces y cortes interpretan la ley, así estará mejor preparado para el ejercicio profesional, conocerá el criterio de quienes están llamados naturalmente a resolver los contenciosos.

Del casojudicial materia de la casación reproducida en la parte final del presente trabajo pueden extraerse, para fines de análisis y reflexión, diversos temas; empero, por evidentes razones de extensión, nos interesa comentar al menos dos de ellos que estimamos medulares: el carácter recepticio de las declaraciones contractuales y, con relación a ello, los alcances de la cláusula resolutoria expresa.

\section{Las declaraciones contractuales son de carácter recepticio}

1. El artículo 1374 del Código Civil de $1984^{1}$ refiere el carácter recepticio de las declaraciones contractuales, entendiéndose como tales a las que se generan en todo el iter contractual: negociación, celebración y ejecución, no sólo en razón de su propio texto sino por interpretación sistemática con el artículo 1362 del señalado código. Por ello, la norma en cuestión refiere a la oferta y a la revocación de la misma (cuando corresponda, en armonía con lo establecido en el artículo 1382 del indicado cuerpo legislativo, debiéndose entender obligatoriedad de la oferta como irrevocabilidad o generación de un estado de sujeción para el oferente, como regla general), así como a la aceptación, que en estricto son declaraciones prenegociales, para luego hacer mención a «cualquier otra declaración contractual».

Adviértase que, con o sin intención, el legislador no hace referencia a una simple manifestación de las partes, como mera exteriorización, sino a una declaración, sobre la base que la respectiva exteriorización de voluntad de los agentes está orientada a producir determinados efectos jurídicos, representados o representables por el emisor, merecedores de tutela ${ }^{2}$. Aunque no deja de ser cierto que los distintos libros del Código Civil refieren indistintamente a manifestación y declaración, no debe dejarse de tener presente

1 De acuerdo al texto aprobado mediante Ley Nro. 27291:

La oferta, su revocación, la aceptación y cualquier otra declaración contractual dirigida a determinada persona se consideran conocidas en el momento en que llegan a la dirección del destinatario, a no ser que este pruebe haberse encontrado, sin su culpa, en la imposibilidad de conocerla. Si se realiza a través de medios electrónicos, ópticos u otro análogo, se presumirá la recepción de la declaración contractual, cuando el remitente reciba el acuse de recibo.

2 ESPINOZA, Juan. Acto Jurídico Negocial. Análisis doctrinario, legislativo y jurisprudencial. Lima, Gaceta jurídica, 2008, p. 49 y ss. 
que el actual Código Civil proviene de un proceso de elaboración de casi veinte años, con textos redactados en momentos distintos, por diferentes autores ${ }^{3}$.

2. Ahora bien, la norma en cuestión fue incorporada en el actual Código Civil tomando como modelo inmediato a la legislación civil italiana de 1942, reproduciendo casi literalmente el artículo 1335 del Codice, conforme al cual «La oferta, la aceptación, la revocación de éstas y toda otra declaración dirigida a persona determinada se reputan conocidas en el momento que arriban a la dirección del destinatario, a menos que éste pruebe que estaba imposibilitado, sin culpa, para tener noticia de ella». Se colige por una simple comparación que, más allá de la redacción, el concepto es el mismo: las declaraciones contractuales sólo surten efecto cuando son puestas en conocimiento de la persona cierta o determinada a la cual se dirigen, presumiéndose dicho conocimiento cuando arriban o llegan a la dirección del destinatario, salvo que éste demuestre que estuvo impedido, sin su culpa, de tomar dicho conocimiento.

Conforme a lo anterior, toda declaración contractual, como puede ser, por ejemplo, una oferta de modificación del negocio ya celebrado, o el ejercicio del derecho potestativo resolutorio en caso de grave incumplimiento obligacional, surtirá efectos (en los casos propuestos, tratándose de la oferta, generando la irrevocabilidad,

3 Dicho proceso estuvo, en un primer momento, a cargo de la denominada «Comisión Reformadora», creada mediante Decreto Supremo Nro. 95 del 1 de marzo de 1965, expedido durante el primer gobierno constitucional del presidente Fernando Belaúnde. A los miembros de dicha comisión se les encargó el estudio y revisión del Código Civil de 1936, esto es, cuando el mismo no había cumplido ni siquiera treinta años de vigencia. Entre sus miembros más renombrados tenemos, en un primer momento, a Carlos Fernández Sessarego, José León Barandiarán, Rómulo Lanatta Güilhem, Héctor Cornejo Chávez y Max Arias-Schreiber Pezet, siendo que de manera posterior se integrarán Felipe Osterling Parodi, Jorge Avendaño Valdez, Lucrecia Maisch Von Humboldt, Manuel de la Puente y Lavalle y Fernando de Trazegnies Granda, entre otros. Si bien el encargo inicial fue proponer modificaciones al Código Civil de 1936, sus miembros optaron finalmente por elaborar y proponer un texto sustitutorio, un nuevo código civil. Los trabajos de esta comisión se extenderán hasta 1981, cuando se presenta al Poder Ejecutivo (segundo gobierno constitucional del presidente Fernando Belaúnde) el respectivo proyecto, que bien puede ser denominado como "primer proyecto». De manera posterior, en un segundo momento, funcionará la denominada «Comisión Revisora», creada por Ley Nro. 23403, promulgada en mayo de 1982, la misma que tenía precisamente por objeto revisar el proyecto elaborado por la Comisión Reformadora. Entre sus miembros más destacados figuraban Javier Alva Orlandini, Roberto Ramírez del Villar, César Fernández Arce y Jack Bigio Chrem. Su competencia fue complementada mediante Ley Nro. 23756, promulgada en diciembre de 1983. Los trabajos de esta comisión se extenderán hasta julio de 1984, cuando se presenta al Poder Ejecutivo el respectivo proyecto (que bien puede ser llamado como «segundo proyecto», elaborado sobre la base del primer proyecto), el mismo que será finalmente promulgado como ley de la república. 
y tratándose de la resolución, extinguiendo la relación obligacional, si se trata de una resolución de pleno derecho en el marco del artículo 1430 del Código Civil) siempre y cuando sea puesta en conocimiento del destinatario, quien debe ser persona cierta o determinada.

Adviértase que el efecto jurídico, representado por el emisor de la declaración de voluntad, sólo se produce legalmente cuando el destinatario de aquélla toma conocimiento de la misma; empero, como puede resultar complejo probar esto último (el tomar conocimiento no se evidencia necesariamente por conductas), el derecho se asiste de una presunción, dando como cierto lo incierto: se reputa que la declaración entregada (con lo cual se está afirmando implícitamente que aquélla debe ser documental, escrita) en la dirección que corresponde al domicilio del destinatario es conocida. Y se trata además de una presunción relativa, siendo que la prueba en contrario radicará en que el destinatario acredite que, por más que haya habido la respectiva entrega, estuvo imposibilitado, sin su culpa, de tomar conocimiento, o que la referida declaración no fue simplemente entregada.

Para establecer los efectos de las declaraciones contractuales nos adherimos, por consiguiente, a la teoría de la cognición o conocimiento, pero asistidos de la teoría de la entrega: la declaración entregada se presume conocida, salvo prueba en contrario, la cual radicará en demostrar la imposibilidad, sin culpa, de tomar conocimiento.

De acuerdo al antecedente italiano y a lo regulado en nuestro Código Civil, la presunción de conocimiento demanda que el emisor de la declaración cuide de entregarla, «desprendiéndose» de ella. Es así que la norma italiana refiere a que la declaración «arribe» a la dirección del destinatario, mientras que nuestro Código Civil demanda que «llegue» a la señalada dirección. Los verbos son concluyentes, están orientados a destacar que se entrega algo en el domicilio del destinatario de la declaración, siendo que ese algo es el documento que contiene la declaración de voluntad.

Mientras ese supuesto de hecho no se verifique, la respectiva declaración contractual documental no surtirá efectos, dado que, al no haber sido entregada, no habrá ingresado al conocimiento del destinatario.

Así como la voluntad sólo trasciende cuando es declarada, produciendo efectos jurídicos, de la misma manera, la declaración sólo 
trasciende cuando es puesta en conocimiento, lo cual se logra al entregarse el documento que la contiene.

3. Retomemos los dos ejemplos referidos anteriormente. Tratándose de una oferta de modificación de contrato, por más que la misma sea autosuficiente y esté dirigida a la contraparte contractual, mientras el declarante no se «desprenda» de su declaración, la misma carece de valor jurídico, dado que sólo desplegará efectos una vez que sea comunicada, puesta en conocimiento del destinatario. Por ello, en nuestro sistema legal, hasta dicho momento el oferente puede retractarse de su declaración, siendo que luego de la puesta en conocimiento, nuestro sistema legal asigna -en principio- a la oferta un carácter irrevocable. Y sólo en caso que la oferta sea revocable, será excepcionalmente viable una declaración sobreviniente de revocación. Y tratándose de la resolución -de pleno derecho, bajo el artículo 1430 del Código Civil-, a través de la cual se extingue la relación jurídico obligacional creada por el contrato, aquélla subsistirá mientras no se comunique a la parte infiel o deudora sobre la decisión de la parte fiel, del acreedor, de dar por concluido el respectivo vínculo. En consecuencia, el hecho que la parte infiel haya incurrido en causal de resolución contractual, o que la parte fiel haya tomado la firme y grave decisión de resolver el contrato (por pérdida de interés en la conducta debida), son irrelevantes, porque lo que interesa es que se declare, se exteriorice, la decisión de extinguir al contrato, poniéndola en conocimiento de quien soportará la resolución.

4. Como bien es sabido, las declaraciones de voluntad pueden categorizarse de diversas maneras, entre ellas, en declaraciones recepticias y no recepticias. En las primeras, los respectivos efectos están subordinados a su puesta en conocimiento de la persona a la cual están dirigidas, lo cual no ocurre en el caso de las segundas.

Sobre el particular, resulta pertinente destacar lo siguiente:

Se dicen «recepticias» aquellas declaraciones que deben enderezadas y llegar a ser conocibles de su destinatario o destinatarios (terceros interesados). Se trata (...) de declaraciones perfectas, jurídicamente relevantes (y, por lo tanto, eficaces) para quien las ha emitido desde el momento de la emisión y de la iniciativa de la notificación a los terceros interesados; e irrelevantes ( $\mathrm{y}$, por ende, ineficaces), en cambio, para los terceros hasta el momento eventual de la recepción y de la conexa conocibilidad legal de la misma declaración.

La naturaleza «recepticia» puede depender esencialmente: (...) de la función que el propio acto declarativo está destinado a desempeñar, en el sentido que la manifestación no tendría relevancia práctica si no fuera enderezada a los terceros y hecha conocer de éstos (por ejemplo, 
una oferta de contrato se puede justificar sólo en cuanto involucre al aceptante o a los posibles interesados) $)^{4}$.

Si la declaración está orientada a desplegar y afectar a un tercero o, sobre la base de un contrato ya celebrado, por relatividad, a la contraparte, es manifiesto que requiere ponerse necesariamente en conocimiento de la persona a la cual va dirigida. En otras palabras, la ley impone una carga, una actuación estructurada en razón del propio interés de quien debe observarla, del emisor de la declaración, en el sentido que su declaración de voluntad sólo desplegará los efectos esperados cuando ingrese a la esfera jurídica de quien se pretenda afectar (en términos amplios o latos, positiva o negativamente), esto es, cuando sea puesta en conocimiento del destinatario, aplicándose la presunción ya referida.

En sentido negativo, la declaración de voluntad no generará efectos legales mientras no sea puesta en conocimiento de la persona a la cual va dirigida.

5. Es más, bien podemos sostener que esta regulación sobre las declaraciones recepticias en el ámbito contractual es una de orden público, porque estructura a nuestro ordenamiento, por lo que deviene en inderogable por la autonomía privada, al igual como ocurre, por ejemplo, con las reglas sobre perfeccionamiento constitutivo, obligatoriedad o relatividad contractual.

No debe olvidarse que, en la larga evolución del rol de la voluntad en la teoría general del contrato, se admite actualmente que aquélla sólo adquiere relevancia cuando es exteriorizada, cuando es conocida por quien se pretende incidir, lo cual ha permitido inclusive construir toda una conceptualización sobre la protección de la confianza generada por la declaración de voluntad ${ }^{5}$, fundamento por ejemplo de la responsabilidad in contrahendo.

6. En el caso judicial que genera el presente trabajo, relativo a un desalojo por ocupación precaria, conforme al cual el demandado habría perdido el título (compraventa) que legitimaba su posesión por haber operado (pretendidamente) la resolución de pleno derecho

4 BIGLIAZZI-GERI, BRECCIA, BUSNELLI y NATOLI, Ugo. Derecho Civil. Hechos y Actos Jurídicos (1. ${ }^{a}$ edición en español) (trad. Fernando Hinestrosa). Tomo I, vol. 2, Bogotá, Universidad Externado de Colombia, 1992, p. 680.

5 Nos remitimos en particular a ROPPO, Vincenzo. El contrato (1. ${ }^{\mathrm{a}} \mathrm{ed}$. peruana, trad. Eugenia Ariano). Lima, Gaceta Jurídica, 2009, p. 60 y ss. Asimismo, resulta interesante revisar el trabajo elaborado por: ESCOBAR, Freddy. «Apuntes sobre la responsabilidad por ineficacia contractual (El caso del artículo 207 del Código Civil peruano)». En: Themis, Revista de Derecho (Segunda Época). Núm. 49, Lima, 2004, pp. 153 a 160. 
del respectivo contrato, sin ingresar (por el momento) a analizar la materia de fondo, esto es, sobre si hubo efectivamente incumplimiento grave o no del correspondiente contrato de compraventa, quedándonos simplemente en el aspecto formal, la cuestión radica en determinar: ¿el vendedor (actual demandante) comunicó o no al comprador, en su momento, la resolución del contrato? o, expresado de otra manera, ¿el comprador tomó conocimiento, en la oportunidad que sostiene el vendedor, de la resolución contractual?

No hay duda, conforme ya ha sido precedentemente destacado, que una declaración de resolución contractual de pleno derecho es de carácter recepticio, por lo que sólo afectará a la esfera jurídica de la contraparte infiel en la medida que sea puesta oportunamente en su conocimiento, para lo cual, sin perjuicio de la necesidad de comunicación a que se refiere el artículo 1430 del Código Civil, resulta aplicable ineludiblemente su artículo 1374.

En tal virtud, sobre la base de los antecedentes del caso, ¿la carta de fecha 2 de octubre de 2013, remitida por don Renzo Escobar Tillit a don Nolberto Solano Todco -la misma que contiene la respectiva declaración de voluntad resolutoria- fue entregada notarialmente en el domicilio del destinatario, operando así la presunción legal de conocimiento sobre su contenido, y los respectivos efectos legales? De acuerdo a los hechos referidos en la jurisprudencia, no. La carta notarial correspondiente no fue entregada, no hay una constancia en dicho sentido (con lo cual, en rigor, la comunicación ni siquiera es una carta notarial); por el contrario, lo que se indica es que una persona que domicilia en el inmueble al que corresponde la dirección contractualmente establecida por la parte compradora, se negó a recibirla. No es que la notaría entregó la carta y el receptor se negó a firmar el respectivo cargo o constancia, o que ante dicha negativa la carta fue igualmente dejada, bajo fe notarial, en la respectiva dirección (dejándose constancia de las circunstancias de dicho diligenciamiento), sino que la comunicación en cuestión no fue entregada (según se aprecia de la propia constancia notarial: «Presente una persona quien no se identificó manifestó que el destinatario ya no domicilia en el inmueble en cuya virtud no se entregó el documento» (énfasis nuestro). Por lo tanto, la declaración de voluntad contenida en dicha carta no surte efectos, al no haber sido exteriorizada conforme a ley, por no haber sido puesta en conocimiento del destinatario (mediante su entrega en la dirección correspondiente, máximo cuando la misma estaba fijada contractualmente). No es suficiente, por consiguiente, destacar que sí se había incurrido en causal de resolución, o que el vendedor había perdido todo interés en mantener la relación contractual, porque 
mientras ello no sea comunicado, puesto en conocimiento, de la contraparte, el contrato sigue vigente, de manera que el comprador no puede ser considerado como un precario.

De acuerdo a los antecedentes narrados en la jurisprudencia bajo comentario, el correspondiente contrato de compraventa no sólo contenía los domicilios señalados por las partes sino el expreso pacto -frecuente en la práctica negocial- en el sentido que las direcciones señaladas por las partes se mantendrían subsistentes salvo que, conforme a lo pactado, se informase sobre cualquier variación, señalándose una nueva dirección, por lo que toda comunicación o notificación dirigida al domicilio consignado se tendría por válida y desplegaría plenos efectos.

Conforme a ello, si la carta en cuestión hubiese sido efectivamente entregada en el respectivo domicilio, conforme a los términos y condiciones contractuales, hubiese desplegado el efecto resolutorio representado por su emisor.

De acuerdo a la propia constancia notarial, al no haber habido «desprendimiento» del documento que contiene la declaración del vendedor, ésta no despliega los efectos representados por su emisor, por lo que no operó la resolución, manteniéndose la relación contractual, con lo cual subsiste la posibilidad que la parte infiel pueda aún cumplir con la obligación a su cargo, pudiendo realizar el respectivo ofrecimiento de pago, siendo además que el comprador mantiene un título para ocupar el respectivo inmueble, por lo que no puede ser considerado como un precario.

Y lo que es más grave, ante dicha subsistencia vincular, el acreedor, parte fiel, no podrá rechazar legítimamente el ofrecimiento de pago (en la medida que cumpla con los requisitos legales correspondientes), por más que hubiese perdido interés en la prestación, por lo que la parte infiel podrá recurrir a mecanismos alternos de pago como la consignación.

Por ello, para evitar encontrase en una situación que sea insostenible para su propio interés, el vendedor (actual demandante) debe exteriorizar oportunamente la pérdida de interés, entregando la declaración de resolución contractual.

7. Aunque hemos hecho énfasis a la necesidad de ese «desprendimiento» documental para que la declaración (escrita) surta efectos legales, lo cual el artículo 1374 del Código Civil hace extensivo a las comunicaciones electrónicas, merece analizarse -en el caso 
concreto- el razonamiento seguido en las instancias judiciales comprometidas.

De acuerdo a los antecedentes referidos en la jurisprudencia bajo comentario, en primera instancia se resolvió declarar infundada la demanda de desalojo debido a que el demandante no cumplió, en su oportunidad, con la formalidad exigida para la resolución contractual de pleno derecho, esto es, con entregar la respectiva comunicación. Adviértase que el juzgado de primera instancia se representaría que la formalidad de la declaración representa satisfacer exigencias legales. No es un tema de formalidad, o exigencia de forma, se trata de un requisito sine qua non, la voluntad debe ser declarada, exteriorizada, publicitada, para que despliegue efectos legales, para que se alcance aquello que se pretende: la extinción del vínculo.

En segunda instancia se modificó ese criterio, porque revocándose la de vista, se declaró fundada la demanda, entendiéndose que sí se cumplió con la pretendida formalidad, y para ello se invocó lo establecido en el artículo 100 de la Ley del Notariado-Decreto Legislativo 1049, según el cual: «El notario certificará la entrega de cartas e instrumentos que los interesados le soliciten, a la dirección del destinatario, dentro de los límites de su jurisdicción, dejando constancia de su entrega o de las circunstancias de su diligenciamiento en el duplicado que devolverá a los interesados». Conforme al criterio de la Sala Civil Transitoria Descentralizada de Ate de la Corte Superior de Lima, atendiendo a que el notario dejó constancia de las circunstancias del diligenciamiento de la respectiva carta (lo cual evidencia inobjetablemente que la carta no fue entregada finalmente), debe concluirse que sí fue cumplida la respectiva formalidad (el requisito de la entrega), no siendo atribuible al demandante que el demandado no viva en la dirección señalada en su oportunidad.

8. Si por formalidad se tiene la exigencia, legal o convencional, de una determinada forma o manera de expresar la voluntad, la formalidad derivada del artículo 1430 del Código Civil (regulación del pacto o cláusula resolutoria expresa) es simplemente una forma escrita ${ }^{6}$, la cual adquiere carácter ad probationem. A ello, por

\footnotetext{
Más allá que, conforme a la reglamentación registral predial (Reglamento de Inscripciones del Registro de Predios, aprobado por Resolución del Superintendente Nacional de los Registros Públicos Nro. 097-2013-SUNARP-SN del 3 de mayo de 2013, para fines de inscripción de la resolución proveniente del régimen regulado en el artículo 1430 del Código Civil, la respectiva comunicación debe ser notarial, lo cual permite tener certeza que en su momento fue efectivamente entregada en el domicilio correspondiente.
} 
lo tanto, no puede referirse el IV Pleno Casatorio recaído en la Casación Nro. 2195-2011 UCAYALI -referido por la Corte Superior en la sentencia de segunda instancia-, debiéndose entender que la referencia a formalidad es que se haya seguido, observado, el respectivo protocolo o procedimiento resolutorio.

Siendo así, lo mínimo o elemental, lo ineludible, es que se verifique si la comunicación que contiene la declaración de voluntad (legítima) de resolver al contrato fue entregada o no al destinatario. De ser entregada, la resolución desplegará sus efectos; de lo contrario, no. Y en el caso bajo comentario, no fue entregada, más allá que el respectivo notario narre las circunstancias bajo las cuales no se pudo realizar la entrega, las circunstancias del frustrado diligenciamiento. Pareciera que la Corte Superior no advierte que, conforme al artículo 100 de la Ley del Notariado, el notario certifica la «entrega» de comunicaciones, no la frustrada entrega o el intento de entrega. Otra cosa, muy distinta, es que la entrega haya sido accidentada, caso en el cual se dejará constancia de cómo se realizó la entrega de la comunicación, de las circunstancias del diligenciamiento. Esa necesidad de dejar constancia del «diligenciamiento» de la entrega explicaría que, en muchos casos, el notario deja constancia que se dejó la respectiva carta debajo de la puerta, o que la entregó, pero se negaron a suscribir el «cargo» correspondiente, por lo que pasa a describir las características físicas del lugar, o indica el número de suministro de los servicios públicos instalados en el respectivo inmueble, etc.

La Sala Civil Transitoria de la Corte Suprema de Justicia de la República sí cuidará de apreciar lo que la Corte Superior no advirtió inexcusablemente.

9. No habiéndose realizado entrega de la comunicación resolutoria, la misma sólo mantiene o surte efectos tratándose del emisor o declarante de voluntad (lo cual, para efectos prácticos, significa muy poco), por lo que el correspondiente contrato de compraventa subsiste, no habiendo fenecido el legítimo título posesorio del comprador. Conforme a ello, resulta manifiesto que, al permanecer vigente el vínculo contractual, deviene en infundada la demanda de desalojo por ocupación precaria.

Esto último será precisamente lo que concluya la instancia suprema en vía de casación. Y su pronunciamiento, desde una perspectiva docente, nos invita a apreciar la exigencia legal del carácter recepticio de las declaraciones de voluntad contractuales, dimensionándola adecuadamente. 


\section{Sobre la cláusula resolutoria expresa}

1. Para estimar los alcances de la cláusula resolutoria expresa, como mecanismo para implementar el remedio de una resolución unilateral por inejecución de obligaciones, debemos hacer una necesaria referencia general a la resolución, así como dos referencias específicas a los conceptos de legitimidad y procedimiento en materia resolutoria.

2. La resolución contractual, como tantas otras figuras jurídicas, puede enfocarse desde dos perspectivas, una extensa y otra restringida. La resolución en sentido amplio implica la extinción del vínculo contractual por causas configuradas posteriormente a su celebración, lo cual permite incluir al desistimiento, a la resolución en sentido estricto, al mutuo acuerdo, a la condición resolutoria, etc. Como no es necesariamente una solución frente a determinado problema, podemos referirnos, siguiendo a calificada doctrina ${ }^{7}$, a una resolución de carácter «no remedial». En cambio, la resolución en sentido estricto o, con carácter remedial, implica que la extinción del vínculo sólo puede obedecer a tres causas o «patologías», cuya nota común es su constitución luego de celebrado el contrato, las que son: imposibilidad, dificultad e incumplimiento.

El artículo 1371 del Código Civil de 1984 define de manera general a la resolución.

3. La resolución remedial a su vez puede operar de pleno derecho o no. El efecto resolutorio de pleno derecho implica que el vínculo contractual queda extinguido por la sola ocurrencia del supuesto de hecho o legal correspondiente, sin necesidad de declaración constitutiva de fuente jurisdiccional; en consecuencia, de haber dicha declaración, la misma será meramente declarativa. Es el mismo tratamiento que es dispensado a la nulidad, o a la condición. Es frecuente que habiendo un conflicto sobre si operó o no la resolución de pleno derecho, ello sea sometido al conocimiento jurisdiccional, lo cual no significa que el juez resuelva al contrato, sino que reconocerá que quedó resuelto.

En materia de imposibilidad total sobreviniente, al tornarse en imposible la ejecución prestacional, el contrato queda resuelto automáticamente, por el solo acontecimiento de la indicada impo-

7 ROPPO, Vincenzo. El contrato (1. ${ }^{a}$ ed. peruana, trad. Eugenia Ariano). Lima, Gaceta Jurídica, 2009, pp. 862 y 863. 
sibilidad, no siendo necesaria comunicación alguna para extinguir al vínculo. Conforme ya hemos señalado, en caso de discrepancias, cualquier declaración jurisdiccional será meramente declarativa, se reconocerá lo que ya se produjo. Y de haber una comunicación, informando sobre la resolución, la misma no será jurídicamente necesaria, al no ser constitutiva.

En materia de incumplimiento prestacional, el efecto de pleno derecho sólo corresponde a la resolución unilateral promovida por la parte agraviada, esto es, por el acreedor que soporta el incumplimiento, dentro de los parámetros de ley, refiriéndonos con esto a los regímenes resolutorios regulados en los artículos 1429 y 1430 del Código Civil, resolución por intimación y pacto resolutorio expreso, respectivamente. La resolución por incumplimiento será de pleno derecho cuando, con arreglo a dichos dispositivos, la invoque el acreedor, operando automáticamente en la medida que se cumpla con las respectivas exigencias legales, requiriéndose necesariamente de invocación, de una específica declaración de voluntad por parte del acreedor agraviado, la misma que debe ser conocida por la contraparte. Y es que la voluntad no declarada es simplemente inexistente. En caso de discrepancias, cualquier declaración jurisdiccional será declarativa, no constitutiva.

4. ¿Por qué la resolución remedial no opera, en estos casos de regulación de pleno derecho, de manera automática por el solo hecho de la inejecución misma incurrida por el deudor? Para responder dicha cuestión estimamos que es fundamental tener presente la figura del denominado «concurso electivo», asociada al hecho que, en toda relación obligacional, la conducta debida, esperada, está orientada a satisfacer exclusivamente el interés del acreedor, siendo ésta la categoría estructuradora de las diversas situaciones subjetivas provenientes del acuerdo de voluntades. En consecuencia, ante una situación de incumplimiento (de lo esperado), en donde aún es posible ejecutar la prestación debida, compete en ese momento al acreedor (titular del crédito, titular del interés que pretende ser satisfecho mediante la ejecución de lo debido por parte del deudor) tomar la decisión extrema, a modo de remedio frente a la patología generada por la inconducta del deudor, de extinguir o no el contrato a título de resolución. En tal virtud, mientras el acreedor agraviado no ejerza dicho derecho potestativo (con la correlativa posibilidad de modificar la situación jurídica de su contraparte), el contrato sigue vigente. Y esa vigencia es la que además se representa el deudor, por más que sea parte infiel, por lo que hay que poner en su conocimiento, la resolución referida. Hay que declarar e infirmar sobre la resolución. 
De acuerdo a lo que ya ha sido destacado precedentemente, en el contexto contractual, donde hay un «otro», ejercer el derecho potestativo resolutorio no es otra cosa que comunicar su ejercicio, de manera que la parte infiel conozca de la pérdida de interés del acreedor, generándose el correlativo impedimento de ejecutar la prestación adeudada al haberse extinguido de pleno derecho el vínculo contraído en su oportunidad.

En efecto, no se trata simplemente que haya un incumplimiento, y que el acreedor opte por la resolución por incumplimiento de pleno derecho, sino que el ejercicio del derecho potestativo debe ser comunicado necesariamente a la contraparte contractual, porque lo que no se exterioriza a la persona cierta o determinada que se pretende afectar, resulta ineficaz frente a ella. Encontrándonos adscritos al principio de relatividad (artículo 1363 del Código Civil: el contrato sólo despliega efectos directos entre sus partes, no frente a terceros), y siendo que la resolución pretende poner fin al vínculo contractual (artículo 1370 del Código Civil), generando los efectos liberatorio, restitutorio y reparatorio que correspondiesen es absolutamente indispensable que el acreedor comunique que ha ejercido su concurso electivo y, conforme a ello, que ha optado por ponerle fin, por extinguir a la relación obligacional. Mientras no lo haga, por más que nos encontremos ante una gravísima inconducta del deudor, por más que con ello se haya materializado el riesgo natural de inejecución que existe en todo contrato, este último seguirá vigente, aunque el acreedor hubiese perdido interés en el cumplimiento de lo debido.

Ahí es cuando se aprecia la dimensión de la regla ya referida sobre el carácter recepticio de las declaraciones contractuales: Lo que no está exteriorizado, comunicado a la persona a la cual se pretende afectar en su esfera jurídica, no está simplemente en este mundo.

Conforme a ello, la formalidad que pudiese entenderse para fines de la implementación de la resolución (siguiendo el lenguaje empleado en la segunda instancia, en el caso judicial bajo comentario) no radica en emplear una determinada forma para que el acreedor exteriorice su decisión, sino en comunicarla a la contraparte contractual para que se represente la terminación o inminente terminación del contrato, según sea que se esté bajo los alcances de los artículos 1430 o 1429 del Código Civil de 1984, respectivamente.

8 ROPPO, Vincenzo. Op. cit., pp. 868-870. 
Mientras ello no se produzca, lo que el deudor infiel aprecia es que, más allá de haber vulnerado el interés del acreedor, éste mantiene al vínculo. Por ello la necesidad de comunicar sobre la resolución contractual a la parte infiel es una auténtica «carga» en cabeza de la parte fiel del contrato, ya que, si pretende lograr la extinción del vínculo, en tiempo oportuno y forma pertinente debe declarar su voluntad a la parte infiel. De lo contrario, bien podremos afirmar que «quien calla, otorga», dado que ante la ausencia de declaración se mantendrá el status quo, el estado de cosas generado por la subsistencia contractual.

En cualquier caso, conviene no dejar de tener presente que un contrato tiene relevancia no sólo entre las partes sino social, de allí que el ordenamiento lo proteja, regulando lo relativo a su formación y terminación, de allí que exista un numerus clausus tratándose de los procedimientos resolutorios.

5. Ahora bien, para la viabilidad jurídica de la resolución por incumplimiento, deben observarse rigurosamente (dado el efecto jurídico que se pretende que es la extinción del vínculo contractual) dos temas: la legitimidad resolutoria y el procedimiento resolutorio.

La legitimidad implica que quien invoca la resolución es, en primer lugar, la llamada parte fiel del contrato, sea bajo lectura positiva o negativa. La lectura positiva se coloca en el supuesto que, en el marco de los contratos sinalagmáticos (donde ambas partes son recíprocamente acreedor y deudor), el acreedor ya ejecutó la prestación que estaba a su cargo, siendo más bien que su contraparte no ha cumplido. La lectura negativa, implica, siempre en el marco sinalagmático, que el acreedor es parte fiel porque no ha incurrido en incumplimiento alguno, dado que la prestación a su cargo está diferida con relación a la exigencia de la contraprestación, por lo que no ha inejecutado su compromiso, a diferencia de su deudor, quien no ha cumplido con lo que ya le era exigible.

La indicada lectura positiva aplica cuando se está ante contratos de ejecución simultánea, siendo que una de las partes (la que será parte fiel) renuncia a dicha simultaneidad y procede a la ejecución de la prestación a su cargo, pudiendo con ello reclamar la contraprestación (constituyendo en mora a su contraparte) y generando la posibilidad de aplicar la regla solve et repete, e inclusive cuando se está ante contratos de ejecución sucesiva, siendo que ya se ejecutó la prestación que debía cumplirse en primer lugar. La lectura negativa aplica más bien ante los contratos de ejecución diferida: ante 
el incumplimiento de la parte que debe cumplir en primer lugar, la que debe cumplir en segundo lugar, quien goza legítimamente del beneficio al plazo, puede reclamar lo adeudado y optar por extinguir al vínculo y lo puede hacer porque no ha violado el autorreglamento de intereses.

En el caso judicial bajo comentario no contamos con información suficiente para formular un juicio sobre si la parte demandante fue, en su momento, con ocasión de optar por la resolución, parte fiel o no. Y es que la resolución se activó por la falta de pago del saldo de precio y falta de firma oportuna de la correspondiente escritura pública (aunque esto último es lo relativo a la cláusula resolutoria expresa pactada en su oportunidad). Entendemos que la vendedora sí fue parte fiel porque habría entregado la posesión del inmueble vendido, pero no podemos dejar de considerar que la cláusula resolutoria expresa invocada se refiere a la suscripción de la escritura pública, cuya exigibilidad era simultánea a una determinada fecha, siendo que la señalada suscripción presupone que la respectiva escritura pública hubiese sido previamente extendida. En el caso existe la mención a que no se habría podido extender la escritura pública porque la parte vendedora no habría entregado los documentos necesarios para ello, de manera que no sería exigible la suscripción al no estar extendida la respectiva escritura pública. Dicho tema no es destacado en el análisis de los hechos contenido en la jurisprudencia bajo comentario, ni habría sido reiterado por la parte demandada, pero no deberíamos obviarlo, de ser el caso.

Pero no basta que quien ejerce el derecho potestativo resolutorio -derivado del concurso electivo por incumplimiento- sea parte fiel, sino que se requiere que se esté ante un efectivo incumplimiento y que éste sea grave, relevante, significativo, sustancial. En nuestro sistema legal, tributario de una tradición in favor debitoris, la falta de cumplimiento no es jurídicamente incumplimiento

9 Por las circunstancias temporales del programa de ejecución prestacional, resulta inaplicable el artículo 1335 del Código Civil, dado que éste tiene como hipótesis de hecho un régimen de ejecución simultánea, como situación ordinaria y que equilibra los intereses de ambas partes, de manera supletoria. Sobre el particular, resultan sumamente ilustrativas las explicaciones que proporciona el maestro DE LA PUENTE Y LAVALLE, Manuel. El contrato en general. Comentarios a la Sección Primera del Libro VII del Código Civil (2a ed.). Tomo II, Lima, Palestra Editores, 2011, pp. 325 y 385. Véase también: LUQUE GAMERO, Ricardo. «Excepción de incumplimiento». En: Temas de Derecho Contractual, Lima, Cusco Cultural, 1987 p. 40 y ss. Conforme a ello, no compartimos definitivamente una lectura que proponga que la noción de parte fiel demanda que el respetivo acreedor haya cumplido necesariamente con la prestación a su cargo. Se trata de un tema fundamental que amerita un estudio de mayor extensión. 
porque éste sólo se evidencia a través de la mora, de manera que mientras ésta no se constituya, lo que de hecho existirá frente a una falta de cumplimiento será un plazo de gracia, de tolerancia respecto al débito pendiente de ejecución, más allá que la mora se configure o no de manera automática. Por consiguiente, falta de cumplimiento no es -en función de lo señalado- incumplimiento, aunque nos parezca un extraño juego de palabras. El incumplimiento es, por consiguiente, una falta de cumplimiento calificado jurídicamente, y ello a través de la mora.

La gravedad del incumplimiento se asocia a la naturaleza remedial de la resolución; sólo debe operar ante aquello que afecta inequívocamente al interés del acreedor, una inconducta trascendente que justifique el remedio extremo de poner fin al contrato entendido como instrumento o vehículo para fines del intercambio económico. Es así que, en el marco de la autonomía privada, son las propias partes las que definen lo que es grave o no, en todo caso, atendiendo a cada tipo negocial, habrá que apreciar cuáles prestaciones son significativas o no, de manera que su incumplimiento autorice, legitime, optar por la resolución.

Sobre la base que se concluya que el acreedor posee legitimidad resolutoria (puede resolver, en pocas palabras), corresponde explorar lo relativo al procedimiento o manera para extinguir al vínculo por causa de inejecución de obligaciones.

La resolución puede ser constitutivamente jurisdiccional o no. La jurisdiccional demanda necesariamente de un pronunciamiento firme y definitivo de un tercero en ejercicio de la función jurisdiccional, de un juez (en sentido lato, sea público o privado), por lo que hasta que ello no ocurra, el contrato no está resuelto o, dicho de otro modo, sigue vigente. Esta resolución está regulada en el segundo párrafo del artículo 1428 del Código Civil de 1984, siendo que desde que se emplaza al deudor demandado (que no es otra cosa que, en el marco de las declaraciones recepticias, desde que se le notifica de la demanda y con ello se le informa sobre la pérdida de interés en lo debido, optándose por la resolución), este último queda impedido de ejecutar lo adeudado, estándose a lo que resulte del proceso en trámite. Por su parte, la resolución extrajurisdiccional corresponde a la resolución unilateral o de pleno derecho que hemos referido anteriormente, en que la ley autoriza a la parte fiel del contrato para que, ante la grave afectación de su interés por la inconducta del deudor, pueda poner fin al contrato observando rigurosamente las reglas contenidas en los artículos 1429 y 1430 del Código Civil, según corresponda. 
Por razones obvias, para efectos del presente trabajo, nos concentraremos en la denominada cláusula resolutoria expresa.

6. La cláusula o pacto resolutorio expreso se encuentra legislado en el artículo 1430 del Código Civil, siendo que sus requisitos configurativos deben ser rigurosamente verificados dado el efecto jurídico irreversible que genera la comunicación de su sola invocación: la extinción del contrato.

De manera sintética dichos requisitos son: la prestación sobre la cual recae el potencial incumplimiento debe estar prevista de manera determinada, precisa, en el respectivo acuerdo. Allí se aprecia el requisito de inejecución grave que ha sido referido anteriormente, dado que las partes acuerdan que el incumplimiento de tal, y no cual, prestación ofende severamente al interés del acreedor y lo autoriza para resolver al contrato celebrado. Expresado de otra manera, el pacto debe contener la indicación que, en caso de incumplimiento de esa, y no otra, prestación, ello legitima a la resolución contractual, entendida ésta como una que operará de pleno derecho, ya que por el sólo mérito de la comunicación que realice el acreedor al deudor infiel, el contrato quedará resuelto.

El artículo 1430 del Código Civil exige de comunicación al deudor. Resulta obvio. Conforme ya ha sido expresado, una cosa es incurrir en causal de resolución y otra, muy distinta, es que el contrato quede efectivamente resuelto. Una cosa es que, habiéndose incurrido en causal de resolución, el acreedor opte por resolver al contrato y otra, muy diferente, es que el contrato haya quedado extinguido. Pretendiéndose impactar en la esfera jurídica del deudor infiel, y siendo que el acreedor, como parte fiel, es titular de un concurso electivo en el marco de un contrato que aún se mantiene vigente, es absolutamente necesario que exteriorice el sentido de su voluntad, su decisión de extinguir al contrato, de resolverlo. Sobre el particular, resulta pertinente lo expresado por reconocida doctrina:

Para que el pacto comisorio produzca efectos se requiere dos presupuestos: el incumplimiento previsto en el pacto; y la comunicación cursada por la parte fiel a la infiel de querer valerse de la resolución.

(...)

(...) la resolución se produce como consecuencia del incumplimiento previsto en el pacto comisorio, pero que es ineficaz, o sea nadie puede valerse de ella, hasta que la parte fiel, mediante su declaración en ese sentido, le concede su efecto resolutorio, el cual actúa de pleno derecho. La declaración de la parte fiel no es, pues, constitutiva de la resolución, sino un requisito (condictio iuris) para su eficacia. 
En ese sentido puede entenderse la opinión de MESSINEO cuando dice «si la declaración no se hiciese, es como si la parte que tiene derecho renunciara a valerse de la resolución», lo que supone que la resolución existe y que la renuncia se refiere exclusivamente a valerse de ella.

La razón de ser de exigir la declaración de la parte fiel es impedir que la parte infiel se valga de su propio incumplimiento para obtener la resolución automática del contrato, con lo cual eludiría el cumplimiento de su prestación y lo reemplazaría por daños y perjuicios, desde que la parte fiel se encontraría imposibilitada de invocar el contrato extinguido (énfasis nuestro) ${ }^{10}$.

En tal virtud, somos de opinión que no resulta posible que, en el marco de la autonomía privada, al convenirse el pacto resolutorio expreso, las partes puedan relevarse de la necesidad de comunicación, dado que ello no sólo contraviene al artículo 1430 del Código Civil, sino que ofende gravemente a su artículo 1374, el mismo que, conforme hemos señalado, contiene una regla del orden público contractual, inderogable.

7. Resulta curioso como la expresión «de pleno derecho» en materia resolutoria puede generar desencuentros, sobre todo en lo que se refiere a los respectivos efectos. Como bien es sabido, el actual Código Civil de 1984 es fruto de un prolongado trabajo de casi veinte años, de distintos legisladores; en primer lugar, a través de la denominada «Comisión Reformadora»y, de manera posterior de la «Comisión Revisora», habiéndose generado en ese proceso ciertos desencuentros, algunos más aparentes que reales ${ }^{11}$.

De acuerdo al proyecto elaborado por la Comisión Reformadora, tratándose del pacto resolutorio expreso, éste operaba de pleno derecho y no demandaba de declaración judicial ${ }^{12}$. Por una cuestión de interpretación sistemática, sobre la base del concurso electivo del cual es titular la parte fiel y, por último, en razón de que, por una elemental razón de razón de buena fe, no puede invocarse el

10 DE LA PUENTE Y LAVALLE, Manuel. El contrato en general. Comentarios a la Sección Primera del Libro VII del Código Civil ( $2^{\text {a }}$ ed.). Tomo II, Lima, Palestra Editores, 2011, pp. 443 y 444 .

11 El tema es importante porque nos encontramos nuevamente en un proceso de reforma del Código Civil de 1984, en donde la mayor tentación es asumir que el «otro» es el equivocado, sin realizar el esfuerzo necesario de representarnos adecuadamente lo que pretende explicar, más allá de las palabras empleadas, que pueden ser equívocas, o en todo caso, de cuestionarnos sobre si la propuesta obedece a una necesidad advertida de los pronunciamientos jurisdiccionales en los últimos decenios. Es muy probable que, si se realiza ese esfuerzo, y se identifica serenamente lo que necesita realmente en el marco de la reforma legislativa, el respectivo trabajo sea mucho más puntual y productivo.

12 Artículo 1453 del respectivo proyecto: «Puede convenirse expresamente que el contrato se resuelva cuando una de las partes no cumpliese determinada prestación a su cargo, establecida con toda precisión. La resolución operará de pleno derecho y no requiere de declaración judicial». 
hecho propio -la propia inconducta, la inejecución obligacionalpara obtenerse la extinción del vínculo, no correspondía representarse de la propuesta que la resolución de pleno derecho era una automática, esto es, que no demandaba de comunicación a la parte infiel. Era manifiesto que, de ejercerse el pacto resolutorio expreso, debía darse avisa a la parte infiel, aunque la norma no lo indicase en el texto correspondiente. Sin embargo, ese no fue el criterio interpretativo seguido por la Comisión Revisora. Si se revisa con atención la Exposición de Motivos Oficial del Código Civil $^{13}$ en materia de los artículos relativos a rescisión y resolución (artículos 1370 al 1372 del Código Civil), se apreciará lo siguiente al comentarse los alcances del actual artículo 1430 del Código Civil de 1984:

El párrafo segundo fue variado sustancialmente por la Comisión Revisora del Código Civil a fin de favorecer al contratante perjudicado por el incumplimiento que puede tener interés en solicitar la ejecución forzada de la obligación, derecho que le estaba vedado con la fórmula que contenía el artículo 1453 del Proyecto de Código Civil de 1981, que recogía una solución similar a la del artículo 569 del Código Civil boliviano.

Con motivo de la aprobación de este precepto el doctor Jack Bigio Chrem expresó que la Comisión Revisora había recibido una sugerencia a fin que se establezca el criterio que la cláusula resolutoria no opere automáticamente, sino que constituya una elección del perjudicado por el incumplimiento. Manifestó que si no se incluía tal indicación, el acreedor podía verse perjudicado ya que ante el incumplimiento del deudor, se originaría automáticamente la resolución del contrato, situación que podía serle inconveniente, agregó que si el artículo 1428 establece una opción en favor del acreedor, la cláusula resolutoria que constituye el medio más expeditivo (en la medida, que no requiere de proceso judicial), lejos de ser un instrumento en su beneficio podía convertirse en un arma en su perjuicio, que por todo ello sostenía que debía incorporarse un segundo párrafo como el que contiene el artículo 1456 del Código Civil italiano, a fin de que la resolución sólo se produzca cuando el interesado ejercita la cláusula resolutoria.

\section{(...)}

La norma permite pacto en contrario. Por lo tanto, es admisible una estipulación según la cual se establezca que basta el incumplimiento de determinada prestación para que se origine la resolución del contrato, sin necesidad de la comunicación a que alude el párrafo segundo, artículo 1430 del Código Civil (énfasis nuestro).

13 COMISIÓN REVISORA DEL CÓDIGO CIVIL DE ACUERDO A LAS LEYES 24039 Y 24136. Exposición de Motivos Oficiales del Código Civil - Rescisión y Resolución de Contratos (Art. 1370, 1371 y 1372 del C. Civil), Separata Especial del Diario Oficial El Peruano, 8 de abril de 1989, pp. 15 y 16. 
¿Podía sostenerse seriamente que la cláusula resolutoria expresa operaba automáticamente por el solo hecho del respectivo incumplimiento?

Puede ser atendible precisar un texto legislativo, pero bajo los conceptos comprometidos sobre las comunicaciones recepticias, del concurso electivo de la parte fiel frente a la grave inejecución de obligaciones y de la propia buena fe contractual, no puede confundirse -en materia específica de incumplimiento- resolución de pleno derecho con resolución automática. Pero lo que es más grave, menos puede postularse que la comunicación de ejercicio del pacto resolutorio expreso es meramente contingente, que opera supletoriamente, pero que no es necesaria, ya que las partes pueden convenir cosa distinta, esto es, que por el solo hecho del incumplimiento el contrato quede resuelto, esto es, resuelto automáticamente.

Esa falta de rigurosidad, trasladándola al plano de la casación bajo comentario, no puede significar asumir que se ha entregado, y puesto en conocimiento del destinatario, aquello, que en la realidad no ha sido entregado, entendiendo (forzadamente) que cuando el notario público deja constancia de las circunstancias por las cuales no se pudo realizar la entrega de la respectiva carta, ello implica dejar constancia de su diligenciamiento, operando una suerte de entrega «ficta».

8. Todas las declaraciones contractuales son recepticias, por lo que mientras no lleguen a conocimiento de la persona cierta a la cual van dirigidas, no despliegan efectos. $\mathrm{Y}$ en materia de incumplimiento, sobre la base de lo sancionado en el propio primer párrafo del artículo 1428 del Código Civil, la parte fiel es titular de un concurso electivo, por lo que le corresponde en su momento optar, declarar y comunicar, qué es lo que decide: mantener el contrato (lo cual opera por defecto) o resolverlo, pero mientras no comunique esto último, el contrato sigue vigente.

Siendo que un contrato no es sino una autorregulación de intereses, en ejercicio de su autonomía privada ¿pueden las partes pactar contra el requisito de comunicar sobre la resolución, o de ponerla en conocimiento? La autonomía privada no es irrestricta, está limitada por las normas imperativas en sentido lato: orden público, buenas costumbres y normas imperativos en sentido estricto, de manera que el interés particular está subordinado al general. La exigencia de comunicar, de informar ciertamente, a la parte infiel del ejercicio del pacto resolutorio expreso, no encuentra 
su fundamento en lo dispuesto en el artículo 1430 del Código Civil, sino en la regla contenida en su artículo 1374, salvo que la ley establezca alguna excepción.

En tal virtud, en el actual proceso de reforma del Código Civil, más allá de la loable intención de resguardar en la mejor medida el interés del acreedor, como parte agraviada por el incumplimiento contractual, pueden resultar inquietantes las propuestas de regular resoluciones automáticas por incumplimiento, ya que en los hechos el deudor -por el solo hecho de su propio incumplimiento- estaría extinguiendo el vínculo, sin perjuicio de la responsabilidad que le fuese exigible, situación que desconoce abiertamente al concurso electivo.

9. Lo expuesto sirve para refrendar la absoluta necesidad que, ante una situación de incumplimiento contractual que legitime el ejercicio del pacto comisorio o resolutorio expreso, la parte fiel cuide (carga, como situación jurídica subjetiva específica de desventaja activa) de comunicar, en tiempo oportuno ( $\mathrm{y}$, de ser el caso, bajo la forma adecuada o correspondiente), sobre su decisión de optar por la extinción del contrato, resolución que operará de pleno derecho, no requiriéndose de manera constitutiva de la intervención jurisdiccional. En consecuencia, si no se puede demostrar que se realizó dicha comunicación, que significa entregar la respectiva declaración contenida en un medio escrito, en una carta -que permite activar la presunción de puesta en conocimiento de la parte infiel-, la pretendida resolución no despliega efectos, por lo que el vínculo subsiste.

Conforme a ello, con buen criterio la Corte Suprema de Justicia de la República resuelve casar la resolución de vista, declarando finalmente (actuando en sede de instancia, por economía procesal) que se confirma la resolución de primera instancia que declaró en su oportunidad infundada la demanda de desalojo por precariedad, dado que el título contractual no ha sido extinguido regularmente.

En síntesis, bien podemos afirmar que, en materia de resolución contractual por incumplimiento, fondo y forma son relevantes; tan importante como la legitimidad es la debida observancia del procedimiento, en el marco de la regla de orden público contractual sobre el carácter recepticio de las declaraciones contractuales. 
CORTE SUPREMA DE JUSTICIA DE LA REPÚBLICA

SALA CIVIL TRANSITORIA

CASACIÓN 1725-2016

LIMA ESTE

\section{DESALOJO POR OCUPACIÓN PRECARIA}

Lima, diecisiete de marzo

de dos mil diecisiete.-

LA SALA CIVIL TRANSITORIA DE LA CORTE SUPREMA DE JUSTICIA DE LA REPÚBLICA: Vista la causa número mil setecientos veinticinco - dos mil dieciséis; en audiencia pública de la fecha; y producida la votación de acuerdo a ley, emite la siguiente sentencia:

\section{ASUNTO:}

Se trata del recurso de casación interpuesto por el demandado Nolberto Albino Solano Todco a fojas doscientos ochenta contra la Sentencia de Vista, contenida en la resolución número cinco, de fecha seis de noviembre de dos mil quince, de fojas doscientos cincuenta y cuatro; emitida por la Sala Civil Transitoria Descentralizada de Ate de la Corte Superior de Justicia de Lima Este; que revoca la sentencia apelada de fecha doce de febrero de dos mil quince, que declara infundada la demanda de Desalojo por Ocupación Precaria; y reformándola declaran fundada; ordenando la restitución del bien inmueble sub litis.

\section{ANTECEDENTES:}

\section{DEMANDA}

Se aprecia que a fojas cincuenta y siete, el demandante Renzo Escobar Tillit pretende que el órgano jurisdiccional ordene al demandado Nolberto Albino Solano Todco, desocupe el inmueble ubicado en el 
Paraíso Número 350, Sector 03 - Casa C, Urbanización El Sol de la Molina. Sustenta su petitorio en:

i. Alega que es propietario del bien acotado por tener derecho inscrito en los Registros Públicos Número 12573096.

ii. Sostiene que, con fecha doce de julio de dos mil trece, en calidad de vendedor celebró con el demandado un CONTRATO DE COMPRAVENTA habiendo acordado el pago de cuatrocientos noventa mil dólares americanos (US\$490,000.00) donde el emplazado entregaría la suma de doscientos cuarenta mil dólares americanos $\mathbf{( \$ 2 4 0 , 0 0 0 . 0 0 )}$ y que éste suscribiría la Escritura Pública el uno de octubre de dos mil trece.

iii. Llegada dicha fecha el demandado no cumplió con el pago ni con la firma de la Escritura Pública por lo que procedió a enviar una carta notarial de fecha dos de octubre de dos mil trece, donde indicaba que el contrato se encontraba RESUELTO en virtud a la cláusula octava del contrato.

iv. Y es en mérito a la cláusula octava que el demandado se obligaba a devolver el bien sub litis a más tardar al día siguiente de la fecha pactada. A la fecha el demandado tiene la calidad de precario.

\section{CONTESTACIÓN DE LA DEMANDA}

Emplazada que fue la misma, Rafael Eduardo Castillo Ismodes en representación de Nolberto Albino Solano Todco contesta la demanda a fojas ochenta y seis, señalando que:

a) La CARTA NOTARIAL NUNCA FUE ENTREGADA EN EL DOMICILIO de su poderdante por ello nunca tomó conocimiento de dicha comunicación, hasta que se le notificó una invitación a conciliar el veintiséis de junio de dos mil catorce, cursada por el Centro de Conciliación Extrajudicial «Gutiérrez» (Expediente número 245-2014), a fin de asistir a una sesión conciliatoria solicitada por el demandante mediante escrito de la misma fecha, en la que el actor recauda la citada carta notarial de fecha dos de octubre de dos mil trece.

b) La carta no fue entregada por el personal de la Notaria, ni fue recepcionada en el domicilio de destino, por ello, su poderdante jamás tuvo conocimiento de ella, por lo que la pretendida resolución de contrato que contiene deviene inválida e ineficaz. 
c) De la certificación notarial se advierte que la CARTA NO LLEGÓ AL DOMICILIO de su poderdante fijado en el CONTRATO y por lo tanto GENERÓ LA INVALIDEZ E INEFICACIA de la pretendida RESOLUCIÓN EXTRAJUDICIAL DEL CONTRATO POR INCUMPLIMIENTO; por esta razón, no es posible invocar la «resolución extrajudicial del contrato», al inobservarse el requisito de validez y eficacia que señala la ley para esta modalidad resolutoria.

d) La resolución contractual también es infundada, ya que la cláusula octava del CONTRATO DE COMPRA VENTA celebrado entre las partes establece que el incumplimiento queda configurado cuando por culpa de su poderdante no se firme la Escritura Pública que la minuta de Compra Venta origine. No se trata de una cláusula resolutoria que apercibe la falta de pago de precio como causal de incumplimiento, sino la falta de firma de la Escritura Pública por razones imputables a su representado, como causal resolutoria específica y única.

e) Que, la MINUTA DE COMPRA VENTA fue ingresada a la Notaría Pública Renzo Alberti el veintiséis de julio de dos mil trece, con número de Kárdex 40516, pero dicha Notaría se vio imposibilitada de culminar la redacción de la Escritura Pública; en primer lugar, porque la parte demandante no entregó a la Notaría Publica los formularios PU y HR del año dos mil trece, que son de cargo del demandante en calidad de vendedor, no entregó la copia certificada de la Partida Registral en la que consta el régimen de Separación de Patrimonios invocado por el demandante, que aparece consignado en la parte introductoria de la MINUTA DE COMPRA VENTA sub litis puesto que manifiesta ser de estado civil casado, no acreditó documental y fehacientemente a su poderdante que había cumplido con levantar la hipoteca.

\section{SENTENCIA DE PRIMERA INSTANCIA}

Culminado el trámite correspondiente, el Juez mediante sentencia de fecha, doce de febrero de dos mil quince, de fojas ciento sesenta y dos, declara infundada la demanda de Desalojo por Ocupación Precaria, sustentando que:

I. Solano Todco a la dirección de Calle Escarpada Número 133 - Urbanización La Alameda de la Planicie, en la que invocando la Cláusula Octava de la Minuta de Compra Venta de fecha doce de julio de dos mil trece, le comunica su decisión irrevocable de Para 
resolver la controversia, tratándose de un proceso de Desalojo por Ocupación Precaria en el caso de resolución extrajudicial del Contrato de Compra Venta, el Cuarto Pleno Casatorio Civil ha establecido como doctrina jurisprudencial vinculante el punto 5.1, en los siguientes términos: [Se consideran como supuestos de posesión precaria] «Los casos de resolución extrajudicial de un contrato, conforme a lo dispuesto por los artículos 1429 y 1430 del Código Civil. En estos casos se da el supuesto de posesión precaria por haber fenecido el título que habilitaba al demandado para seguir poseyendo el inmueble. Para ello bastará que el Juez, que conoce del proceso de desalojo, verifique el cumplimiento de la formalidad de resolución prevista por la ley o el contrato, sin decidir la validez de las condiciones por las que se dio esa resolución. Excepcionalmente, si el Juez advierte que los hechos revisten mayor complejidad, podrá resolver declarando la infundabilidad de la demanda, mas no así la improcedencia».

II. A fojas diecisiete, se tiene el cargo de la CARTA NOTARIAL, de fecha dos de octubre de dos mil trece (ingresada a la Notaría Gutiérrez Adrianzén, el tres deoctubre de dos mil trece) remitida por Renzo Escobar Tillit a Nolberto Albino resolver el contrato, por INCUMPLIMIENTO de pago del SALDO del precio de venta pactado y de su obligación de SUSCRIBIR la respectiva Escritura Pública, conforme a lo establecido en la Cláusula Tercera de dicho contrato, por lo que solicita se le restituya de inmediato el inmueble, para tomar posesión y ejecutar las condiciones pactadas en la cláusula novena del contrato, invocando el artículo 1430 del Código Civil; sin embargo, a fojas diecisiete (vuelta) corre la CERTIFICACIÓN NOTARIAL de fecha once de octubre de dos mil trece, en la que se indica que el original de la presente carta fue diligenciada a la dirección indicada «... Presente una persona quien no se identificó manifestó que el destinatario ya no domicilia en el inmueble en cuya virtud no se entregó el documento»; en consecuencia, la COMUNICACIÓN NO FUE ENTREGADA A SU DESTINATARIO.

III. Sobre este extremo, el Contrato de Compra Venta contenido en la Minuta ingresada con Kárdex 40516 a la Notaria Alberti, obrante de catorce a dieciséis, en su cláusula octava establece la posibilidad que el contrato sea resuelto de pleno derecho cuando por causas imputables al comprador no se suscriba la Escritura Pública de Compra Venta hasta el plazo señalado en la cláusula tercera del presente contrato, [uno de octubre de dos mil trece] en cuyo caso el comprador se obliga a entregar el inmueble materia de Compra Venta en el mismo estado en 
que lo recibió a más tardar al día siguiente de la fecha pactada para la firma de la Escritura Pública, bastando una comunicación por parte del vendedor con su decisión de resolver el contrato; asimismo el artículo 1430 del Código Civil, que regula la cláusula resolutoria expresa que establece que puede convenirse expresamente que el contrato se resuelva cuando una de las partes no cumple determinada prestación a su cargo, establecida con toda precisión. La resolución se produce de pleno derecho cuando la parte interesada comunica a la otra que quiere valerse de la cláusula resolutoria.

IV. En tal sentido al verificar el cumplimiento de la formalidad de la resolución en la forma prevista en la cláusula octava del Contrato de Compra Venta y el artículo 1430 del Código Civil, se arriba a la conclusión de que no se ha cumplido con la citada formalidad, al no haberse comunicado a la parte contraria que quiere valerse de la cláusula resolutoria para que se dé el supuesto de posesión precaria por haber fenecido el título que habilitaba al demandado para seguir poseyendo el inmueble; debiendo tenerse presente el hecho de que la carta notarial nunca fue entregada en el domicilio del demandado y por ello es que no tomó conocimiento de dicha comunicación para que opere la resolución contractual.

V. Con posterioridad se produjo la invitación a conciliar extrajudicialmente, siendo notificada la parte contraria, con fecha veintiséis de junio de dos mil catorce, mediante notificación cursada por el Centro de Conciliación Extrajudicial «Gutiérrez» (Expediente 245-2014) a fin de asistir a una sesión de conciliación extrajudicial solicitada por el demandante, en la que se adjunta la copia de la carta notarial de fecha dos de octubre de dos mil trece; sin embargo, ello no cumple con la formalidad requerida pues el artículo 1430 del Código Civil al ser claro que la resolución se produce de pleno derecho cuando la parte interesada comunica a la otra que quiere valerse de la cláusula resolutoria; solo así será eficaz la resolución de pleno derecho del contrato que justificaba la posesión del demandado para convertirse ahora en ocupante precario.

VI. De otro lado, la solicitud para conciliar no es una prueba, sino es un requisito de la demanda de Desalojo por Ocupante Precario previsto en el artículo 6 de la Ley Número 26872 - Ley de Conciliación, consecuentemente los documentos recaudados con la solicitud de conciliación a que se refiere el demandante no cumplen la formalidad de la comunicación que establece el 
artículo 1430 del Código Civil y, que las partes han pactado en la cláusula octava del contrato de Compra Venta.

\section{RESOLUCIÓN DE SEGUNDA INSTANCIA:}

La Sala Civil Transitoria Descentralizada de Ate de la Corte Superior de Justicia de Lima Este, mediante resolución número cinco, de fecha seis de noviembre de dos mil quince, obrante a fojas doscientos cincuenta y cuatro, revoca la apelada que declara infundada la demanda y reformándola la declaró fundada, ordenando la restitución del bien inmueble sub litis, sustentando:

i. Se verifica que en el contrato de Compra Venta el demandado señaló su DOMICILIO en la Calle Escarpada Número 133, Urbanización Alameda de la Planicie La Molina; así como también de la CARTA NOTARIAL DE FECHA DOS DE OCTUBRE DE DOS MIL TRECE y que fuera DILIGENCIADA AL NOTARIO con la que se pone en conocimiento que se ha resuelto el CONTRATO DE COMPRAVENTA del bien inmueble celebrado entre ambas partes, en ella se consignó dicha dirección para diligenciarla y conforme a los términos de la certificación que obra en el recurso se consigna que «el original de la presente carta fue diligenciada a la dirección ubicada presente una persona que no se identificó manifestó que el destinatario ya no domicilia en el inmueble» en cuya virtud no se entregó el documento.

ii. Que, efectuado el análisis de la certificación realizada al acto de diligenciamiento detallado en el considerando anterior ante Colegiado llega a establecer que se ha cumplido con la formalidad para dar por resuelto el Contrato de Compra Venta del bien inmueble celebrado entre ambas partes por cuanto se ha diligenciado la mencionada carta en el domicilio indicado por el demandado, diligencia que se encuentra amparada en el artículo 100 de la Ley Notariado - Decreto Legislativo Número 1049 que señala: "El notario certificará la entrega de cartas e instrumentos que los interesados le soliciten, a la dirección del destinatario, dentro de los límites de su jurisdicción, dejando constancia de su entrega o de las circunstancias de su diligenciamiento en el duplicado que devolverá a los interesados», no siendo atribuible al demandante de que en el momento de dicha diligencia ya no domicilie el demandado en la dirección señalada por éste en el Contrato de Compra Venta antes mencionado, máxime si no ha alegado que aun domiciliaba en dicha dirección, ni menos que haya puesto en conocimiento al demandante de su nuevo domicilio de con- 
formidad con lo previsto por el artículo 40 del Código Civil, por lo que es de concluir que se ha cumplido con la formalidad que exige el IV Pleno vinculante ya mencionado, por lo que en tal sentido el demandado deviene en precario al haberse resuelto el contrato de Compra Venta de fecha doce de julio de dos mil trece, de conformidad con el artículo 1430 del Código Civil.

iii. Estando a lo alegado se concluye que el titulo ha fenecido por lo que concurre el elemento dispuesto en el artículo 911 del Código Civil.

\section{MATERIA JURÍDICA EN DEBATE:}

a) El tema en debate radica en determinar si el Contrato de Compra Venta suscrito por las partes se ha resuelto, para determinar si se configura el supuesto de posesión precaria.

\section{FUNDAMENTOS:}

PRIMERO.- Siendo que por auto de calificación de fecha dieciséis de junio de dos mil dieciséis del cuadernillo de casación, se declaró procedente el recurso de su propósito por las causales de: i) Infracción normativa material por aplicación indebida del artículo 1374 del Código Civil.- Sostiene que la Sala Superior inobserva la formalidad necesaria que exige el artículo 1430 del Código Civil para tener por cumplido el protocolo resolutorio en los casos de la llamada resolución extrajudicial por incumplimiento. Pues en el presente caso el actor señala que la resolución del contrato ejercitada al amparo de la cláusula resolutoria pactada por las partes fue articulada mediante la remisión de la Carta Notarial de fecha dos de octubre de dos mil trece, diligenciada por el Notario Público el tres de dicho mes y año; sin embargo, es el caso que dicha Carta jamás fue entregada en su domicilio y nunca supo que fue invitado para conciliar, por lo que debe tenerse presente que el Código Civil señala que las comunicaciones producen efecto cuando llegan al domicilio del destinatario; ii) Apartamiento inmotivado del IV Pleno Casatorio recaído en la Casación Número 2195-2011-Ucayali.- La Sala incumple con el mismo, pues pese a que se tiene acreditada la inobservancia de la formalidad para dar por resuelto un contrato al amparo de lo resuelto por el artículo 1430 del Código Civil, la Sala invoca el precedente a fin de sostener que cabe el desalojo por precario cuando se ha resuelto el contrato extrajudicialmente, obviando la formalidad que el mismo precedente exige para ser analizado por el juzgador. 
SEGUNDO.- Del mismo modo, se advierte que este Colegiado Supremo, ha declarado procedente el recurso de casación de su propósito por la procedencia excepcional del artículo 139 incisos 3 y 5 de la Constitución Política del Perú.

TERCERO.- Cuando se invocan en forma simultánea agravios consistentes en la infracción normativa procesal e infracción normativa material que inciden directamente sobre la decisión de la resolución impugnada, resulta innecesario emitir pronunciamiento respecto del segundo agravio denunciado, atendiendo a que, de ampararse el primero deberá declararse la nulidad de la resolución impugnada y ordenarse que se expida un nuevo fallo.

CUARTO.- Bajo este contexto, es menester señalar que, de la revisión de la Sentencia de Vista, tenemos que la decisión adoptada se encuentra adecuadamente fundamentada, pues establece la relación de hecho en base a su apreciación probatoria, interpreta y aplica las normas que considera pertinentes, por lo que no se advierte trasgresión alguna al Principio de Debida Motivación de las Sentencias, no se afecta la Logicidad, ni se vulnera el Derecho a Probar en cualquiera de sus vertientes. Es decir, su pronunciamiento se ha ceñido estrictamente a lo aportado, mostrado y debatido en el proceso, por lo que dicho fallo no puede ser cuestionado por ausencia o defecto en la motivación, pues se ha cumplido con precisar el por qué y debido a qué se ha llegado a la conclusión final, en consecuencia, un parecer o criterio distinto al que ha arribado no puede ser causal para cuestionar la motivación; lo que no significa que no pueda existir un criterio distinto para arribar a una conclusión diferente a la que ha planteado la Sala Superior, sin que ello implique ausencia o defecto en la motivación de la sentencia de vista. En consecuencia, la infracción normativa procesal y excepcional por ausencia de motivación debe ser desestimada en todos sus extremos.

QUINTO.- Siendo esto así, pasaremos a absolver los agravios de orden material, como es la infracción normativa del artículo 1374 del Código Civil que prescribe: «La oferta, su revocación, la aceptación y cualquier otra declaración contractual dirigida a determinada persona se consideran conocidas en el momento en que llegan a la dirección del destinatario, a no ser que éste pruebe haberse encontrado, sin su culpa, en la imposibilidad de conocerla. Si se realiza a través de medios electrónicos, ópticos $u$ otro análogo, se presumirá la recepción de la declaración contractual, cuando el remitente reciba el acuse del recibo». En principio, podemos sostener que nuestro Código Civil acoge la teoría de la cognición, puesto que el artículo 1373 establece que el contrato queda perfeccionado (celebrado) en el momento y lugar en que la aceptación es 
conocida por el oferente ${ }^{14}$. Sin embargo, según el artículo denunciado, es factible señalar que el Código también acoge la Teoría de la Recepción con presunción de cognición, puesto que, a tenor del mencionado artículo, toda declaración contractual -y dentro de ellas, la aceptación- se considera conocida al momento en que llega a la dirección del destinatario, es decir, del oferente, a no ser que este pruebe haberse encontrado, sin su culpa, en la imposibilidad de conocerla.

SEXTO.- En este contexto, tenemos que las partes accionantes en la presente materia, suscribieron un Contrato de Compra Venta con fecha doce de junio de dos mil trece, en calidad de vendedor Renzo Escobar Tillit y en calidad de comprador Nolberto Albino Solano Todco, habiendo acordado el pago de cuatrocientos noventa mil dólares americanos $(\$ 490,000.00)$, suma de dinero que el comprador cancelará al vendedor de la siguiente manera:

a) La suma de doscientos cincuenta mil dólares americanos (US\$250,000.00) serán cancelados por medio de la compensación de la deuda que mantiene el vendedor hacia el comprador de acuerdo al Contrato Mutuo, celebrado entre las partes con fecha catorce de noviembre de dos mil doce, por cuanto el comprador declara mediante el presente documento que, a la fecha de suscripción del presente contrato, el vendedor no mantiene ninguna deuda pendiente por concepto del Contrato de Mutuo antes mencionado.

b) La suma de doscientos cuarenta mil dólares americanos (US\$240,000.00) serán cancelados mediante cheque de gerencia a la firma de la correspondiente Escritura Pública de Compra Venta, la misma que deberá ser suscrita a más tardar el uno de octubre de dos mil trece. Asimismo, en su cláusula octava, establece la condición resolutoria, en el que se indica que el presente contrato será resuelto de pleno derecho en caso que por causas imputables al comprador no se suscriba la Escritura Pública de Compra Venta, hasta el plazo señalado en la cláusula tercera del presente contrato, en cuyo caso el comprador se obliga a entregar el inmueble materia de Compra Venta en el mismo estado en el que recibió a más tardar al día siguiente de la fecha pactada para la firma de la Escritura Pública, bastando una comunicación por parte del vendedor con su decisión de resolver el contrato. Del mismo modo, la cláusula décimo primero esta-

14 Código Civil Comentado. Comentan 209 especialistas en las diversas materias de derecho civil (3 $3^{\text {ed. }}$ ) Tomo VII - Contratos, Lima, Gaceta Jurídica, 2010, p. 179. 


\begin{abstract}
blece que toda comunicación o notificación que, con motivo del presente contrato deba ser cursada a cualquiera de las partes, se entenderá válidamente efectuada si ésta es dirigida a los domicilios consignados en la introducción del presente documento. Cualquier modificación a los domicilios indicados, deberá ser notificada a la otra parte, con una anticipación no menor de tres días hábiles. En caso contrario, toda comunicación o notificación realizada a los domicilios indicados en la introducción del presente documento, se entenderá válidamente efectuada para todos los efectos. Se concluye entonces, que la cláusula resolutiva expresa, solo producirá sus efectos de pleno derecho cuando las causas sean imputables al comprador, bastando una comunicación por parte del vendedor de resolver el contrato en el domicilio señalado en el contrato que los vincula.
\end{abstract}

SÉTIMO.- Obra en el expediente a fojas nueve, una Carta Notarial, de fecha dos de octubre de dos mil trece, remitida por don Renzo Escobar Tillit a don Nolberto Albino Solano Todco, en el que le señala; «En virtud de la Cláusula Resolutoria Expresa contenida en la Cláusula Octava de la Minuta de Compra Venta de fecha doce de julio de dos mil trece, celebrada por ambas partes e ingresada para su escrituración en la Notaría Pública de Lima del Doctor Renzo Alberti, le comunicó la decisión irrevocable de RESOLVER el contrato, toda vez que, hasta la fecha usted no ha cumplido con su obligación de pago del saldo del precio de venta pactado ascendente a doscientos cuarenta mil dólares americanos (US\$240,000.00), ni con su obligación de suscribir la respectiva Escritura Pública a más tardar el uno de octubre de los corrientes, conforme lo establecido en la Cláusula Tercera de dicho contrato, pese a nuestros reiterados requerimientos» (el sombreado es nuestro).

OCTAVO.- Dicha carta fue enviada a la residencia sito en la Calle Escarpada Número 133, Urbanización «La Alameda de la Planicie», domicilio fijado por el emplazado en el Contrato de Compra Venta antes señalado. Se advierte del mismo modo, en el reverso de la carta la certificación notarial que reza: "Que el original de la presente carta fue diligenciado a la dirección indicada presente una persona que no se identificó, manifestó que el destinatario ya no domicilia en el inmueble en cuya virtud no se entregó el documento. Se deja constancia que la diligencia se realizó a las diez horas (10:00). Doy fe. Lima once de octubre de dos mil trece». (El sombreado es nuestro).

NOVENO.- En tal sentido, para verificar el cumplimiento de la formalidad de la resolución en la forma prevista en la cláusula octava del Contrato de Compra Venta de acuerdo a las exigencias del artículo 1430 del Código Civil, es necesario que se tenga que cumplir 
la condición previamente establecida, y de esa manera se entienda que el contrato se ha resuelto, es decir, la resolución tendrá efectos, cuando la parte interesada comunique a la otra que quiere valerse de la cláusula resolutoria.

DÉCIMO.- En el caso de autos, de la comunicación notarial de fecha dos de octubre de dos mil trece, remitida por don Renzo Escobar Tillit a don Nolberto Albino Solano Todco, en el que le comunica su decisión irrevocable de resolver el Contrato de Compra Venta, no se puede tener certeza absoluta de que haya surtido sus efectos, ello si tenemos en cuenta que conforme se advierte de su certificación notarial la comunicación no fue entregada al domicilio del emplazado y si bien es cierto, se ha dejado constancia de las circunstancias de su diligenciamiento, conforme el artículo 100 del Decreto Legislativo Número 1049, hay dudas respecto de su comunicación efectiva. Esta tesis, se sustenta aún más en el hecho de que la emplazada recién tomó conocimiento de dicha comunicación cuando se le notificó una invitación a conciliar con fecha veintiséis de junio de dos mil catorce, cursada por el Centro de Conciliación Extrajudicial «Gutiérrez» Expediente número 245-2014 a la dirección del domicilio consignado en el contrato aludido, no siendo válido que para algunas ocasiones el demandado ya «no viva» en dicho inmueble, y para otras «siga viviendo", prueba de ello es que realmente si ha existido conocimiento de la notificación para conciliar. Entonces, tal como se puede advertir de la certificación notarial, dicha carta no fue entregada por el personal de la Notaría, ni fue recepcionada en el domicilio de destino, existiendo dudas respecto de la validez o invalidez de la pretendida resolución de contrato, por lo que resulta evidente que el caso de autos, resulta complejo, pues no toca en este proceso analizar si se configuró o no la resolución de contrato, en la medida que existe incertidumbre respecto de su comunicación.

DÉCIMO PRIMERO.- Siendo esto así, y en atención al precedente vinculante, punto 5.1 «Para ello, bastará que el Juez, que conoce del proceso de desalojo, verifique el cumplimiento de la formalidad de resolución prevista por la ley o el contrato, sin decidir, la validez de las condiciones por las que se dio esa resolución. Excepcionalmente, si el Juez advierte que los hechos revisten mayor complejidad, podrá resolver declarando la infundabilidad de la demanda, más no así, la improcedencia» y atendiendo a que la naturaleza de la resolución de contrato es disímil a la naturaleza del presente proceso, es que la misma deviene en infundada. 


\section{DECISIÓN:}

Por los fundamentos precedentes y en aplicación de lo establecido por el artículo 396 del Código Procesal Civil, declararon: FUNDADO el recurso de casación interpuesto por Nolberto Albino Solano Todco a fojas doscientos ochenta; en consecuencia; CASARON la recurrida de fecha seis de noviembre de dos mil quince, de fojas doscientos cincuenta y cuatro, que revoca la apelada que declara infundada la demanda y, reformándola declaró fundada la demanda, ordenando la restitución del bien; $y$ actuando en sede de instancia; CONFIRMARON la apelada que declara infundada la demanda de Desalojo por Ocupación Precaria; DISPUSIERON la publicación de la presente resolución en el Diario Oficial «El Peruano», bajo responsabilidad; en los seguidos por Renzo Escobar Tillit contra Nolberto Albino Solano Todco, sobre Desalojo por Ocupación Precaria; y los devolvieron. Ponente Señor De La Barra Barrera, Juez Supremo.-

S.S.

MENDOZA RAMÍREZ

ROMERO DÍAZ

CABELLO MATAMALA

MIRANDA MOLINA

DE LA BARRA BARRERA 